\title{
EPIDEMIOLOGY OF ADULT MEASLES IN NORTH KERALA
}

\author{
Sheela Mathew ${ }^{1}$, Junais Koleri²
}

1Additional Professor, Department of Infectious Diseases, Government Medical College Hospital, Kozhikode, Kerala. ${ }^{2}$ Assistant Professor, Department of Infectious Diseases, Government Medical College Hospital, Kozhikode, Kerala.

\section{ABSTRACT}

\section{BACKGROUND}

Measles is an acute viral infection characterised by fever, cough, rhinorrhoea, conjunctival congestion and maculopapular rash. Disease occurs as epidemic and it is described from all countries. The precise incidence estimates are not available either because of under-reporting or due to lack of surveillance. In temperate zones, measles causes seasonal peaks in early spring and late winter. In tropical zones, most cases occur during dry season. In India, most cases occur during winter and early spring. The disease is considered as disease of children.

Objectives of this study were-

1. To identify the seasonal trend in measles incidence.

2. Age distribution of the disease.

\section{MATERIALS AND METHODS}

This was an observational study during a 10-year period from 2007 - 2016 in a tertiary care centre. Patients above 13 years admitted in the centre with a clinical diagnosis of measles were included in the study.

\section{RESULTS}

There were a total of 809 measles cases. 717 patients were in the age group of 13 - 30 with very few cases more than 40 years of age and there was a male predominance. There were no measles patients above 50 years. Measles incidence was maximum during November to March.

\section{CONCLUSION}

Contrary to the belief that measles is a disease of children, more cases occur now in adolescents and young adults in this part of the country. This is mainly because of single dose measles vaccination implemented in universal immunisation program. The efficacy of single dose vaccine is $85 \%$. In order to reduce transmission, the level of herd immunity needed is about $93 \%-95 \%$. Hence, a single dose vaccine will not provide the needed immunity. Measles in adults affects younger population generally. Diagnosis of measles in those above 40 years of age should be made with caution. Measles incidence follows a seasonal trend. Cases are maximum during September to April months with a peak during winter months when relative humidity is low.

\section{KEYWORDS}

Adult Measles, Epidemiology of Measles, Immunisation.

HOW TO CITE THIS ARTICLE: Mathew S, Koleri J. Epidemiology of adult measles in North Kerala. J. Evolution Med. Dent. Sci. 2018;7(07):901-903, DOI: 10.14260/jemds/2018/205

\section{BACKGROUND}

Measles is an acute highly contagious viral infection caused by Rubeola virus. Only humans are affected and the secondary attack rate approaches $90 \%$. The period of infectivity is 5 days before appearance of rash to four days afterwards. Measles infection can cause a variety of clinical syndromes. This includes classic measles in immunocompetent patients, modified measles in patients with pre-existing but incompletely protective anti-measles antibody, neurologic syndromes following measles infection like A/C disseminated encephalomyelitis and sub-acute sclerosing panencephalitis and severe measles in immunocompromised patients. The incubation period is 6 21 days with a median 13 days. Virus enters through respiratory mucosa or conjunctiva.

'Financial or Other Competing Interest': None.

Submission 05-01-2018, Peer Review 30-01-2018,

Acceptance 05-02-2018, Published 12-02-2018.

Corresponding Author:

Dr. Sheela Mathew,

Government Medical College Hospital,

Kozhikode, Kerala.

E-mail: shaarongardens@yahoo.com

DOI: $10.14260 /$ jemds $/ 2018 / 205$
After a brief local replication, it reaches regional lymph nodes and from there to entire reticuloendothelial system via blood stream, thereby producing a viraemia. The dissemination of the virus due to viraemia with associated infection of endothelial, epithelial, monocyte and macrophage cells may explain the variety of clinical manifestations and complications that can happen with infection. A second viraemia occurs several days after the first, coinciding with the appearance of symptoms signalling the beginning of prodromal phase. The prodrome lasts for 24 days. During this period fever, malaise, anorexia, conjunctival congestion, sneezing, rhinorrhoea and cough can occur. The respiratory symptoms result from mucosal inflammation from viral infection of epithelial cells. About 2 days before onset of rash, patients may develop an enanthem characterised by Koplik's spots. These are 1 - 3 $\mathrm{mm}$ whitish, greyish or bluish elevations with an erythematous base, typically seen on buccal mucosa opposite molar teeth, but they can be seen over the palate, buccal and labial mucosa. Koplik's spots may coalesce and slough later when exantheme appear. Koplik's spots may not be present in all patients, but if present it is diagnostic. The rashes appear 2 - 4 days after onset of fever. Rashes are erythematous and maculopapular, begins on face and spread downwards. Initially rashes blanch, later do not. This 
craniocaudal progression of rash is typical of measles, often palms and soles are not involved. Severe respiratory symptoms may be present during this time. Lymphadenopathy and splenomegaly may be seen. After 3-4 days, rash fade and severely affected area may show desquamation. Fading occur in the same order as it appeared. Cough may persist for another 1 - 2 weeks. The persistence of fever after $4^{\text {th }}$ day may suggest a complication. Both humoral and cellular immunity is important in viral clearance and protection. Individuals with $\mathrm{T}$ cell deficiencies have severe measles infection and high mortality rate. After infection, there is life-long immunity. Following measles infection, there is a transient suppression of $\mathrm{T}$ cell response. So there may be secondary bacterial and viral illnesses which cause the high incidence of mortality and morbidity following measles. Also there may be a reactivation of latent TB.

Individuals with non-protective immunity to measles can develop modified measles. ${ }^{1}$ Recipients of intravenous immunoglobulin, a sub-optimal level of measles antibody following vaccination, prior history of measles in rare instances and transplacental transfer of maternal antibody can cause modified measles. ${ }^{1}$ The clinical presentations of measles in immune compromised patients are atypical. Rashes may be absent or severe and desquamative. Purpura may be present. When an immune compromised patient present with pneumonia or encephalitis, especially after contact with measles there should be high suspicion of measles. Giant cell pneumonia and measles inclusion body encephalitis are described in immune compromised patients.

The differential diagnosis includes other exanthematous viral fevers like varicella, erythema infectiosum, hand foot and mouth disease and rubella. Drug eruptions, rickettsial fevers, IMN, Mycoplasma pneumonia and vasculitic disorders are other differentials.

Complications- Gastrointestinal complications include Diarrhoea, gingivostomatitis, hepatitis, mesenteric adenitis and appendicitis. Pulmonary complications include pneumonia, laryngotracheobronchitis and bronchiolitis. Long term complications like bronchiectasis can occur. Secondary bacterial infections also do occur. Pulmonary complications are most frequent in very young children and adults. Neurologic complications associated with measles include encephalitis, acute disseminated encephalomyelitis and sub-acute sclerosing panencephalitis. Ocular complications include keratitis and corneal ulcerations. Cardiac complications include myocarditis and pericarditis. Individuals with malnutrition, vitamin A deficiency, pregnancy and immune compromised people are more prone for complications.

Laboratory findings include Leucopoenia, Thrombocytopenia and normal ESR. Lymph node biopsy may show reactive changes. Chest $x$-ray may show evidence of pneumonia.

The management of measles is supportive. There is no specific antiviral therapy. Supportive therapy includes antipyretics, fluids and antibiotics if secondary bacterial infection. Vitamin A deficiency contributes to delayed recovery and high rate of complications. Supplementation of Vitamin $\mathrm{A}$ is associated with decreased mortality and morbidity.

Classic measles with typical symptoms and signs is easily diagnosed clinically. A laboratory diagnosis is needed when the clinician is inexperienced, when an unexplained and non-responding pneumonia occurs in an immune compromised person or when presentation is not classical. Disease occurs as epidemic and it is described from all countries. As per WHO, 1/3 rd of measles death is from India. ${ }^{2}$ Disease spread by respiratory droplets and is highly infectious. It may not even need person to person contact as the infectious droplets can remain in air for one to two hours. In temperate zones, measles causes seasonal peaks in early spring and late winter. Droplets remain in air for prolonged periods during conditions of low relative humidity, which may be the reason why the disease is more common during winter. In tropical zones, most cases occur during dry season. Even now the disease is considered as disease of children. In developed countries, the widespread use of measles vaccine in young children has shifted the age trend towards young adults. This study attempts to find out the seasonal trend and age distribution of adult measles in North Kerala.

\section{Aim of the Study}

1. To identify the seasonal trend in measles incidence.

2. Age distribution of the disease.

\section{MATERIALS AND METHODS}

This was an observational study, collecting the data from the inpatient register and case records of patients admitted in ID ward of Calicut Govt. Medical College Hospital with clinical diagnosis of measles during a 10-year period from 2007 2016. Ours is a tertiary care centre catering to 5 northern districts of Kerala. The population covered is about 12 million. Patients above 13 years are admitted in our centre. Paediatric patients are admitted in another institution attached to this centre.

\section{RESULTS}

There were a total of 809 measles cases during the study period. Most of the cases were in the age group of 13 - 30 with very few cases more than 40 years of age and there was a male predominance. There were no measles patients above 50 years. Measles incidence was maximum during November to March. Admissions were either for a diagnostic dilemma or a complication. None of the patients gave a definite vaccination history. It is classically described as when measles occurs in adults, it is associated with many complications. There were two deaths during the study period; both were immune compromised patients receiving steroids and other immune suppressants and both had pneumonia. Tracheobronchitis, bronchospasm and laboratory evidence of liver involvement were the main complications observed. Leucopoenia or leucocytosis was unusual, but thrombocytopenia was observed. A few had evidence of pancreatitis. No case of encephalitis was noted. Gastrointestinal manifestations like diarrhoea, vomiting or both described as a part of clinical syndrome was observed in $>90 \%$ patients.

\begin{tabular}{|c|c|c|c|c|c|c|c|c|c|c|c|}
\hline \begin{tabular}{|c|} 
Age \\
Group
\end{tabular} & 2007 & 2008 & 2009 & 2010 & 2011 & 2012 & 2013 & 2014 & 2015 & 2016 & Total \\
\hline $13-20$ & 66 & 21 & 33 & 70 & 32 & 7 & 36 & 31 & 48 & 13 & 357 \\
\hline $21-30$ & 44 & 19 & 37 & 45 & 57 & 10 & 61 & 24 & 44 & 19 & 360 \\
\hline $31-40$ & 6 & 2 & 6 & 10 & 4 & 2 & 11 & 9 & 21 & 13 & 84 \\
\hline \begin{tabular}{|l|}
$41-50$ \\
\end{tabular} & 2 & 0 & 0 & 1 & 0 & 0 & 1 & 0 & 2 & 2 & 8 \\
\hline$>50$ & 0 & 0 & 0 & 0 & 0 & 0 & 0 & 0 & 0 & 0 & \\
\hline Total & & & & & & & & & & & 809 \\
\hline \multicolumn{12}{|c|}{$\begin{array}{c}\text { Age Distribution of Measles Cases is shown in the Table } \\
\text { and Graph Below }\end{array}$} \\
\hline
\end{tabular}




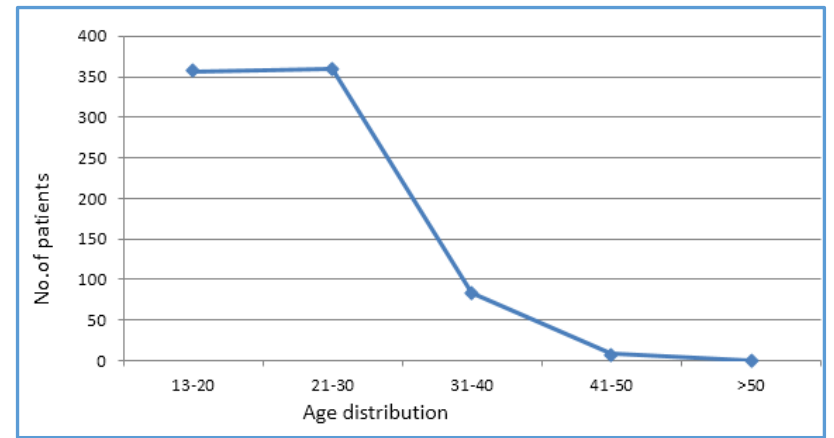

\begin{tabular}{|c|c|c|c|c|c|c|c|c|c|c|c|}
\hline 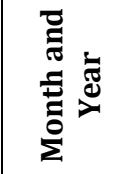 & 옹 & 串 & O̊ & 옹 & 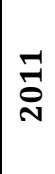 & 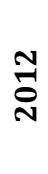 & $\stackrel{m}{\stackrel{n}{0}}$ & ষ্ঠ & 롱 & 뭉 & $\begin{array}{l}\text { 표 } \\
0\end{array}$ \\
\hline January & 9 & 10 & 9 & 15 & 13 & 0 & 9 & 19 & 7 & 8 & 99 \\
\hline \begin{tabular}{|l|} 
February \\
\end{tabular} & 7 & 2 & 5 & 15 & 17 & 3 & 11 & 9 & 13 & 10 & 92 \\
\hline March & 12 & 1 & 5 & 9 & 28 & 2 & 9 & 7 & 14 & 8 & 95 \\
\hline April & 7 & 3 & 9 & 10 & 5 & 2 & 2 & 7 & 6 & 5 & 56 \\
\hline May & 9 & 2 & 2 & 14 & 3 & 5 & 4 & 4 & 16 & 3 & 62 \\
\hline June & 6 & 4 & 8 & 5 & 4 & 1 & 9 & 1 & 10 & 1 & 49 \\
\hline July & 4 & 2 & 5 & 8 & 1 & 0 & 6 & 5 & 6 & 1 & 38 \\
\hline August & 11 & 1 & 1 & 8 & 0 & 0 & 2 & 1 & 6 & 2 & 32 \\
\hline September & 14 & 4 & 4 & 7 & 3 & 1 & 14 & 3 & 9 & 0 & 59 \\
\hline October & 15 & 4 & \begin{tabular}{|l|}
7 \\
\end{tabular} & 9 & 6 & 1 & 9 & 0 & 11 & 2 & 64 \\
\hline November & 12 & 4 & 4 & 16 & 9 & 1 & 15 & 6 & 6 & 2 & 75 \\
\hline December & 13 & 5 & 18 & 11 & 5 & 3 & 19 & 2 & 11 & 1 & 88 \\
\hline
\end{tabular}

Month Wise Distribution of Measles Cases

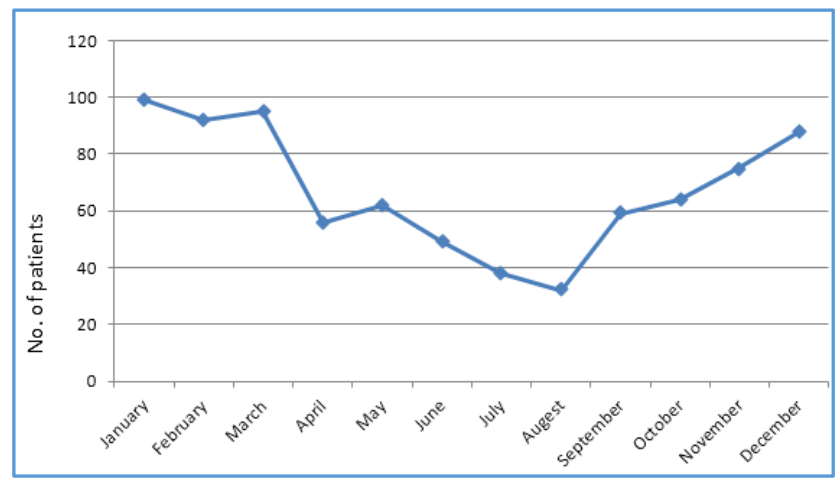

\section{DISCUSSION}

Measles is endemic in all parts of the world and it is a significant cause of mortality and morbidity. Measles continues to be an important cause of childhood morbidity and mortality in many states in India also. ${ }^{3}$ The precise incidence estimates are not available either because of under-reporting or due to lack of surveillance. Given a chance, virus can spread in any season. In India, most cases occur during winter and early spring. A decreased incidence in rainy seasons may be due to increase in relative humidity. In our part also, measles incidence follows a seasonal trend; cases are maximum during September to April with a peak during winter months when relative humidity is low. On an average, humidity is around $84 \%$ during monsoon season in Kerala and it is around $70 \%$ in winter months.

Although, measles immunisation is an effective strategy to prevent cases, outbreak can continue to occur especially in densely populated areas mainly involving adults. India along with 10 other members of WHO SEAR has committed to eliminate measles by 2020. Before the availability of vaccination measles infection was nearly universal and more than $90 \%$ of population was immune by 15 yrs. Following widespread use of vaccination, there is a shift of susceptible population from childhood to adolescence and adulthood.

Contrary to the belief that measles is a disease of children, more cases occur now in adolescents and young adults in this part of country. Measles in adults affects younger adult population generally. Diagnosis of measles in those above 40 years of age should be made with caution. The increased incidence in young adults is mainly because of single dose measles vaccination implemented in universal immunisation program. The efficacy of single dose vaccine is $85 \%{ }^{3,4}$ In order to reduce transmission, the level of herd immunity needed is about $93 \%-95 \%$. Hence, a single dose vaccine with $100 \%$ coverage administered at 9 months of age will not prevent the accumulation of a susceptible pool and consequent periodic measles outbreaks. Seroconversion rate improves to $>95 \%$ when the vaccine is given after one year of age, but the first dose has to be given earlier to protect infants. For these reasons WHO and UNICEF recommended that all national immunisation programs provide 2 doses of measles vaccine for all children. ${ }^{5}$ The purpose of the second dose is to seroconvert the nonseroconverters of first dose. In a phased manner, Govt. of India is working on this goal. Routine immunisation includes 2 doses of measles vaccine. Catch-up vaccination campaigns through supplementary immunisation activities are also materialised. Ensuring all children receive a second dose vaccine, delivered either through supplementary immunisation targeting age $1-14$ yrs. or routine immunisation will definitely reduce the incidence and country will reach the goal of elimination.

\section{CONCLUSION}

Contrary to the belief that measles is a disease of children, more cases occur now in adolescents and young adults in this part of country. This is mainly because of single dose measles vaccination implemented in universal immunisation program. Measles in adults affects younger population generally. Diagnosis of measles in those above 40 years of age should be made with caution. Measles incidence follows a seasonal trend. Cases are maximum during September to April months with a peak during winter months when relative humidity is low.

\section{REFERENCES}

[1] Shrivastava SRB, Shrivastava PS, Ramasamy J. Measles in India: challenges \& recent developments. Infection Ecology \& Epidemiology 2015;5:27784.

[2] WHO vaccine-preventable diseases: monitoring system, global summary, 2008.

[3] Gupta SK, Sosler S, Haldar P, et al. Introduction strategy of second dose measles containing vaccine in India. Indian Peadiatrics 2011;48(5):379-82.

[4] John TJ, Choudhury P. Accelerating measles control in india: opportunity and obligation to act now. Indian Peadiatrics 2009;46(11):939-43.

[5] World Health Organization. Meeting of the Immunization Strategic Advisory Group of Experts, November 2008- conclusions and recommendations. Weekly Epidemiol Rec 2009;84:1-16. 